\title{
The Impact of Care Specialty on Survival-Adjusted Medical Costs of COPD Patients After a Hospitalization: a longitudinal analysis
}

\author{
Wenjia Chen, $P h D^{7}$, Don D. Sin, MD ${ }^{2,3}$, J. Mark FitzGerald, $M D^{3,4,5}$, and Mohsen Sadatsafavi, \\ $M D, P h D^{1,4}$ for the Canadian Respiratory Research Network
}

\begin{abstract}
'Collaboration for Outcomes Research and Evaluation, Faculty of Pharmaceutical Sciences, University of British Columbia, Vancouver, BC, Canada; ' ${ }^{2}$ ivision of Respiratory Medicine, Department of Medicine, The UBC Centre for Heart Lung Innovation, St. Paul's Hospital, University of British Columbia, Vancouver, BC, Canada; ${ }^{3}$ Institute for Heart and Lung Health, Division of Respiratory Medicine, Faculty of Medicine, University of British Columbia, Vancouver, BC, Canada; ${ }^{4}$ Centre for Clinical Epidemiology and Evaluation, University of British Columbia, Vancouver, BC, Canada; ${ }^{5} \mathrm{BC}$ Division of Respiratory Medicine, Department of Medicine, The Lung Centre, Gordon and Leslie Diamond Health Care Centre, Vancouver, BC, Canada.
\end{abstract}

BACKGROUND: Little is known about the impact of care provider's specialty on the medical costs of COPD patients over time.

OBJECTIVE: To compare the long-term medical costs between newly hospitalized COPD patients whose postdischarge care was initiated by a pulmonary specialist versus by a general practitioner.

DESIGN: Retrospective matched cohort study.

PARTICIPANTS: We identified patients with an incident COPD-related hospitalization from the administrative health database (January 1, 1996, to December 31, 2012) of British Columbia, Canada.

MAIN MEASURES: Patients were categorized as receiving specialist care or primary care within the first 90 days after discharge from an incident COPD-related hospitalization. Using propensity scores, we matched each patient who initially received specialist care to a patient who received primary care based on demographics, COPD severity, comorbidity, and admission time. A survival-adjusted, multi-part generalized linear model was used to estimate direct medical costs (in 2015 Canadian dollars, [\$], including inpatient, outpatient, pharmacy, and community care costs) as overall and as COPD-specific and comorbidity-related costs over the following 5 years.

KEY RESULTS: The sample included 7710 patients under each group. The initial specialist-care recipients had a modestly higher 5-year survival than the generalist-care recipients $(0.564$ [95\% CI $0.535,0.634$ ] vs 0.555 [95\% CI $0.525,0.625] ; P<.001)$. Meanwhile, the former incurred $\$ 2809$ higher all-cause medical costs over 5 years compared to the latter $(95 \%$ CI \$2343, \$2913; $P<.001)$,

Prior abstract publication/presentation An earlier version of this manuscript was presented as a poster in the Annual General Meeting of the Canadian Respiratory Research Network on January 12, 2017 in Ottawa, ON, and in the Canadian Respiratory Conference on April 28, 2017 in Montreal, QB, Canada.

Electronic supplementary material The online version of this article (https://doi.org/10.1007/s11606-018-4406-x) contains supplementary material, which is available to authorized users.

Received July 11, 2017

Revised December 8, 2017

Accepted March 8, 2018

Published online April 2, 2018 mainly driven by higher medication costs (difference $\$ 1782$ [95\% CI \$1658, \$1830]; $P<.001)$ particularly related to COPD medications (\$1170 [95\% CI \$1043, $\$ 1225] ; P<.001)$. Specialist care recipients also incurred higher costs of COPD-related hospitalization (\$1144 [95\% CI \$650, \$1221]; $P<.001)$.

CONCLUSIONS: Compared to generalist care, specialist care following COPD hospitalization is slightly more expensive, mainly driven by medication costs especially COPD-specific medications. Future studies should compare differences in health-related quality of life and COPD functional status.

KEY WORDS: COPD; specialty of care; healthcare costs; longitudinal analysis.

J Gen Intern Med 33(9):1528-35

DOI: $10.1007 / \mathrm{s} 11606-018-4406-\mathrm{x}$

(c) Society of General Internal Medicine 2018

\section{INTRODUCTION}

Chronic obstructive pulmonary disease (COPD) is characterized by persistent airflow limitation and an accelerated decline in lung function over time ${ }^{1}$ and is also associated with increased risk of comorbidities and death. ${ }^{2}$ As one of the leading causes of hospitalization in most developed countries, ${ }^{3,4}$ COPD is predicted to become globally the third leading cause of death by $2030 .^{5}$ Consequently, COPD imposes a heavy economic burden on patients and society. 6,7 Appropriate provision of good-quality care to the COPD population should take into account both the growing patient needs and the limited social budgets on healthcare.

In Canada, general practitioners (e.g., family physicians) are the main care providers for most COPD patients, ${ }^{8}$ though one fifth of patients receive care regularly from specialists (i.e., pulmonologists or internists with pulmonary focus). Generalists may provide lower-cost care with greater accessibility and breadth of knowledge than care by specialists, ${ }^{9}$ which can be beneficial for managing the complex comorbidity present in many COPD patients. ${ }^{10,11}$ On the other hand, with greater content expertise, specialists are expected to have more up-to-date knowledge about effective COPD treatments for different 
patients. ${ }^{11,12}$ To date, few studies have examined the differences between primary care and specialist care in COPD management in terms of patient survival or long-term medical costs, which are clinically- and policy-relevant indicators for decision makers. Due to the high long-term mortality rate of COPD,${ }^{13}$ any difference in survival rates between the two groups can potentially bias the estimates of cost differences. ${ }^{14}$ The purpose of the current study is to compare the long-term survival-adjusted medical costs of patients whose post-discharge care was initiated by a pulmonary specialist versus those who received care from a generalist, following an acute COPD exacerbation-related hospitalization.

\section{METHODS}

\section{Data Sources}

Data were obtained between January 1, 1996, and December 31, 2012 (University of British Columbia Human Ethics Certificate H13-00684) from the provincial health administrative databases of British Columbia (BC), a large province in Canada with 4.4 million residents as of $2011 .^{15}$ These databases provide linked, individual-level data on health-care encounters of all legal $\mathrm{BC}$ residents, including inpatient and outpatient services, dispensed prescription medications, community care services, demographics, vital statistics, and registration status. ${ }^{16-21}$ Previous analyses have shown a low prevalence of missing data, under-reporting, and misclassification in these databases. ${ }^{22}$ All inferences, opinions, and conclusions drawn in this study are those of the authors and do not reflect the opinions or policies of the Data Steward(s).

\section{Study Design and Sample}

This was a retrospective matched cohort study of COPD patients who experienced an incident episode of acute exacerbation of COPD leading to hospitalization (Online Appendix 1, schematic presentation of study design). Using a highly specific case definition, ${ }^{23}$ we first identified patients who experienced an incident hospitalization with COPD as the primary discharge diagnosis (International Classification of Diseases, 9th edition [ICD-9]: 491.xx, 492.xx, 493.2x, 496.xx; ICD-10: J43.xx, J44.xx), referred to as the index hospitalization. To restrict our sample to new hospitalizations, we only included patients who were registered in the provincial health-care system (defined as being registered for at least 300 days of the year) for at least 3 years prior to the index hospitalization. To reduce the risk of a false positive diagnosis, we excluded patients who were below 40 years of age as of the index hospitalization (Online Appendix 2, flowchart of cohort creation).

\section{Exposure: Ascertainment of Post-Discharge Care Specialty}

Care specialty was assessed within 90 days after discharge from the index hospitalization, during which we retrieved information for respiratory-related outpatient visits (primary diagnosis code, ICD-9: 491.xx, 492.xx, 493.xx, 496.xx, 784.1x, 784.7x, 786.xx;
ICD-10: J43.xx, J44.xx, J45.xx, J46.xx, R05.xx, R06.xx, R07.1x, R07.8x, R08.xx, R09.0x, R09.1x, R09.2x, R09.3x). Such exposure ascertainment is in line with the principle of "intention to treat (ITT)" analysis in clinical trials ${ }^{24}$ and has been used to assess care specialty and outcomes in asthma. ${ }^{25}$

Online Appendix 3 describes the methods in detail. Each outpatient claim was associated with a specialty code describing the practitioner's specialty. Specialists were defined as pulmonologists and internists specialized in pulmonary diseases. Generalists were general practitioners including family physicians and general internists. We categorized patients as under specialist care if they had at least one respiratory outpatient visit with the specialty code of a respirologist or an internist specialized in respiratory medicine. Otherwise, they were categorized as under generalist care if all respiratory care during this period was provided by family physicians or general internists. Given the hierarchy of referral (from generalists to specialists), patients who received both generalist and specialist care were categorized under the specialist group. Patients with no respiratory-related outpatient visits during this period were excluded from subsequent analyses.

\section{Propensity Score Matching}

We performed 1:1 propensity score matching using a multivariate logistic regression model with exposure as the dependent variable. Matching variables included age, sex, neighborhood household income, and health services delivery area in the calendar year of the index hospitalization, COPD complexity [Online Appendix 4$]^{26}$ and number of COPD-specific physician visits and medications, Charlson Comorbidity Index (excluding COPD $)^{27}$ and number of non-COPD hospitalizations, outpatient visits and medications in the 12-month prior to index hospitalization, severity of the index hospitalization (resource-intensityweight [RIW], length of hospital stay, whether being admitted to intensive care unit), and the calendar year and season of index hospitalization. Based on the nearest propensity scores, we matched each patient in specialist care cohort to a distinct patient in primary care cohort, with differences in their scores no greater than 0.01 .

\section{Outcome: Survival-Adjusted Direct Medical Costs}

The main outcomes were all-cause, COPD-related, and nonCOPD-related (referred to as comorbidity-related) direct medical costs, adjusted to 2015 CAD (\$). To avoid immortal time bias, cost measurement period started on the 91st day after discharge from the index hospitalization (immediately after the exposure ascertainment window). Patients were followed in the data to the date of their death, no longer fully registered in the databases, or the end of the study period (December 31, 2012), whichever came the earliest. The follow-up time for each patient was divided into continuous 3-month intervals, with the last truncated periods discarded unless death occurred. The last complete interval was censored if death had not occurred. 
All-cause medical costs were the sum of four components: hospitalizations, outpatient services, dispensed prescription medications, and community care services. The cost of hospitalization was calculated by multiplying the RIW with the average costs of hospitalizations in BC for the same fiscal year. ${ }^{28}$ Costs of outpatient services, medication dispensations, and community care were directly available in the data. ${ }^{29,30}$ Most $(78 \%)$ of the emergency service costs were captured by fee-for-service payments to health professionals within outpatient services costs (e.g., billing codes with emergency visits/consultation and 1-day onsite hospital visits), with the rest captured within hospitalization costs. ${ }^{31}$ COPD-related costs included costs of hospitalizations and outpatient services records with COPD as the primary diagnosis and costs of major COPD-specific medications (Online Appendix 5, pre-populated medication list. Comorbidity-related costs were calculated as the differences between all-cause and COPDrelated medical costs.

\section{Statistical Analysis}

All analyses were performed with SAS 9.4 (SAS Institute Inc., Cary, NC, United States). Differences in the distribution of matching variables between two cohorts were compared using the standardized difference (with difference $\leq 0.10$ defined as satisfactory matching for that variable). ${ }^{32}$ As an explanatory analysis, we reported the patterns of COPD-related medication within the exposure window. A Poisson regression analysis was conducted to compare differences in the counts of dispensed medications between the two cohorts.

Details of regression analyses are provided in Online Appendix 6. We used a survival-adjusted, multi-part model to estimate the long-term medical costs in COPD patients. ${ }^{14}$ This model adjusts for differential survival and appropriately handles rightcensored, zero-inflated, right-skewed cost data, as well as early deaths and high costs prior to death. ${ }^{14}$ The first part of the model estimated patients' probability of survival up to a given followup time using an accelerated failure time model, accounting for censoring. Survival curves obtained from this model for both groups were plotted and compared. In the second and third part, we used generalized linear models to estimate medical costs when, respectively, patients survived through or died within each interval. Generalized estimating equation was applied to account for correlated observations within matched pairs. The effects of care specialty on survival-adjusted medical costs were estimated by a specific causal inference technique developed by Austin and Urbach, ${ }^{33}$ with confidence intervals and $P$ values obtained from 50 rounds of bootstrapping. Physician-level confounders were adjusted in the analyses, including the baseline total- and COPD-related practice volume of patient's main care provider (Online Appendix 7).

\section{RESULTS}

The original sample constituted of 8394 and 16,922 patients whose post-discharge care was initiated by pulmonary specialists or generalists, respectively. The final sample included 7710 COPD patients under each group. The two cohorts were similar, as the standardized differences of variables included in the propensity score matching were all well below $0.10^{32}$ (Table 1).

Table 1 Selected Baseline Characteristics of the Propensity-ScoreMatched Study Cohorts

\begin{tabular}{|c|c|c|c|}
\hline & \multicolumn{2}{|c|}{$\begin{array}{l}\text { Patients with an incident } \\
\text { COPD hospitalization }\end{array}$} & \multirow[t]{2}{*}{$\begin{array}{l}\text { Standardized } \\
\text { difference }\end{array}$} \\
\hline & $\begin{array}{l}\text { Received } \\
\text { specialist } \\
\text { care }(N= \\
7710)\end{array}$ & $\begin{array}{l}\text { Received } \\
\text { primary } \\
\text { care }(N= \\
7710)\end{array}$ & \\
\hline \multicolumn{4}{|l|}{ Demographics } \\
\hline $\begin{array}{l}\text { Age, mean (SD), } \\
\text { year }^{\dagger}\end{array}$ & $71.0(10.6)$ & $70.9(11.6)$ & 0.00 \\
\hline Sex, no. $(\%)$ & & & -0.01 \\
\hline Female & $3754(49)$ & $3723(48)$ & \\
\hline Male & $3956(51)$ & $3987(52)$ & \\
\hline \multicolumn{4}{|c|}{ Variables related to severity of index hospitalization } \\
\hline \multicolumn{3}{|c|}{$\begin{array}{l}\text { Admitted to ICU at } \\
\text { index } \\
\text { hospitalization, no. } \\
(\%)\end{array}$} & -0.01 \\
\hline No & $7074(92)$ & $7061(92)$ & \\
\hline Yes & $636(8)$ & $649(8)$ & \\
\hline $\begin{array}{l}\text { RIW of index } \\
\text { hospitalization, } \\
\text { mean (SD) }\end{array}$ & $0.97(1.49)$ & $0.97(1.06)$ & 0.00 \\
\hline \multicolumn{3}{|c|}{ Variables related to COPD severity } & \\
\hline $\begin{array}{l}\text { Length of stay at } \\
\text { index }\end{array}$ & $6.2(7.2)$ & $6.3(6.5)$ & -0.01 \\
\hline \multicolumn{3}{|l|}{$\begin{array}{l}\text { hospitalization, } \\
\text { mean (SD), days }\end{array}$} & \\
\hline \multicolumn{3}{|l|}{$\begin{array}{l}\text { COPD complexity, } \\
\text { no. }(\%)^{\ddagger}\end{array}$} & 0.00 \\
\hline Low & $5291(69)$ & $5279(68)$ & \\
\hline Moderate & $1765(23)$ & $1777(23)$ & \\
\hline High & $654(8)$ & $654(8)$ & \\
\hline No. of pre-index & $3.3(4.0)$ & $3.3(4.4)$ & -0.00 \\
\hline \multicolumn{4}{|l|}{$\begin{array}{l}\text { COPD-related phy- } \\
\text { sician visits, mean } \\
(\mathrm{SD})^{\ddagger}\end{array}$} \\
\hline No. of pre-index & $11.4(13.7)$ & $11.1(14.5)$ & 0.02 \\
\hline \multicolumn{4}{|c|}{$\begin{array}{l}\text { COPD-related med- } \\
\text { ication dispensa- } \\
\text { tions, mean (SD) }\end{array}$} \\
\hline \multicolumn{4}{|c|}{ Variables related to comorbidity } \\
\hline Charlson & $1.6(1.7)$ & $1.6(1.7)$ & 0.00 \\
\hline \multicolumn{4}{|l|}{ Comorbidity } \\
\hline \multicolumn{4}{|l|}{ Index ${ }^{\ddagger}$, excluding } \\
\hline COPD, mean (SD) & & & \\
\hline $\begin{array}{l}\text { No. of pre-index } \\
\text { non-COPD hospi- } \\
\text { talization, mean } \\
\text { (SD) }\end{array}$ & $0.7(1.2)$ & $0.7(1.2)$ & 0.00 \\
\hline $\begin{array}{l}\text { No. of pre-index } \\
\text { non-COPD physi- } \\
\text { cian visits, mean } \\
\text { (SD) }\end{array}$ & $29.4(22.1)$ & $29.8(23.9)$ & -0.01 \\
\hline $\begin{array}{l}\text { No. of pre-index } \\
\text { non-COPD medica- } \\
\text { tions, mean (SD) }\end{array}$ & $46.0(119.3)$ & $47.2(97.4)$ & -0.01 \\
\hline
\end{tabular}

SD standard deviation

*Difference in means or proportions divided by standard error. Imbalance was defined as absolute value $>0.10$. Comparing the specialist care cohort versus primary care cohort

${ }^{\top}$ Measured on the day of index COPD hospitalization

*Measured in the past 12 months prior to the index COPD hospitalization 
In the 90-day exposure-ascertainment window, compared to generalist care recipients, patients under specialist care more frequently filled dispensations for inhaled corticosteroid (ICS)/long-acting $\beta$ agonists (LABA) combination therapy (0.78 vs 0.49$)$, long-acting muscarinic antagonists (LAMA) ( 0.40 vs 0.23$)$, and LABA alone ( 0.24 vs. 0.14$)(P<0.001$ for all comparisons in the Poisson regression model, Fig. 1).

Approximately half of the cohort survived to 5 years. Compared to those under generalist care, patients under specialist care had a modestly better survival (5-year survival probability 0.564 vs 0.555 , difference 0.0093 [95\% CI $0.0088-0.0094$, $P<.001$ ], Fig. 2).

Table 2 displays the survival-adjusted medical costs and components by post-discharge care specialty. The specialist care cohort consistently incurred higher all-cause medical costs than the generalist care cohort (1-year difference \$748/ person [95\% CI 605, 767], 5-year difference \$2809/person [95\% CI 2343, 2913]), which was mainly driven by their generally higher medication costs (\$478 [95\% CI 428, 487], $\$ 1782$ [95\% CI 1658, 1830] for 1- and 5-year differences, respectively). $P$ values were less than 0.001 for all excess cost estimations.

The major components of overall cost gap included higher costs of COPD-related medications and hospitalizations, comorbidity-related medications and outpatient visits in the specialist group (5-year differences $\$ 1170$ [95\% CI 1043, 1225], \$1144 [95\% CI 650, 1221], \$870 [95\% CI 824, 889], $\$ 789$ [95\% CI 782, 797], respectively). However, the specialist group spent less on community care and comorbidityrelated hospitalizations compared to the generalist group (5year differences $-\$ 515$ [95\% CI -592 to -231$],-\$ 182$ [95\% CI -200 to -160$]$, respectively). These cost gaps were

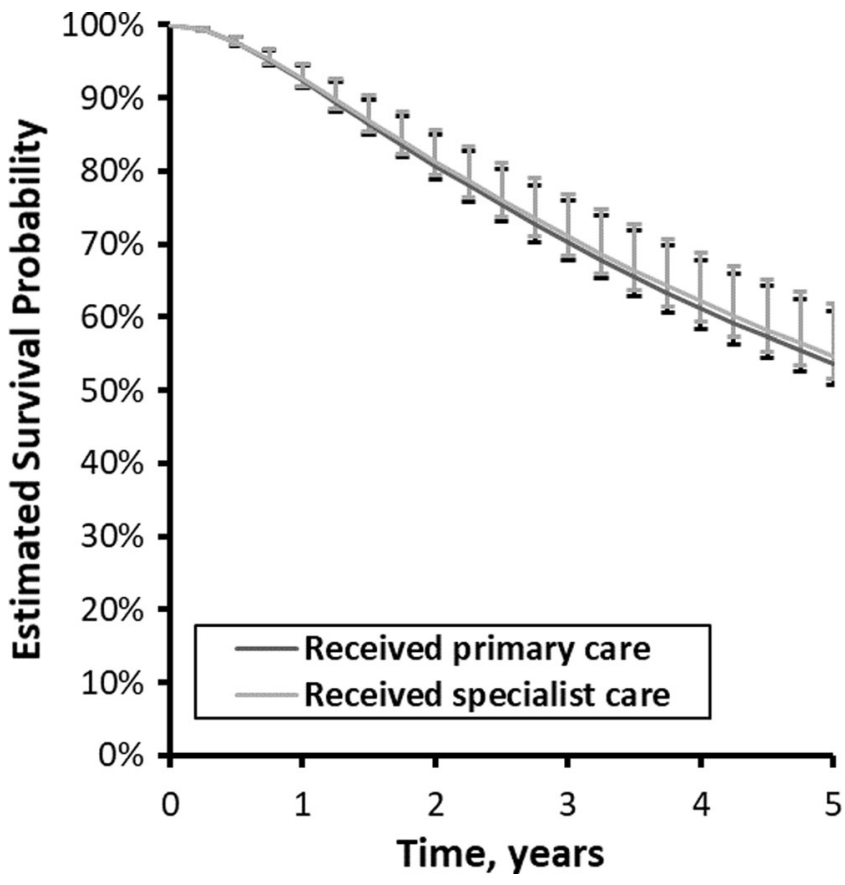

Fig. 2 AFT-estimated survival probabilities of patients following an incident COPD hospitalization, by the specialty of patient's care provider who initiated post-discharge care. AFT accelerated time failure model (the first part of the cost estimation model as used in this study). Error bars indicate $95 \%$ confidence interval.

proportionately smaller in the first year, but the patterns remained generally consistent (Table 2).

Figure 3 shows the cost trajectory plots. Differences in annual costs for COPD-related expenses between the specialist and generalist groups were high in the first year and gradually reduced over time, whereas the annual gap stayed consistent for comorbidity-related costs.

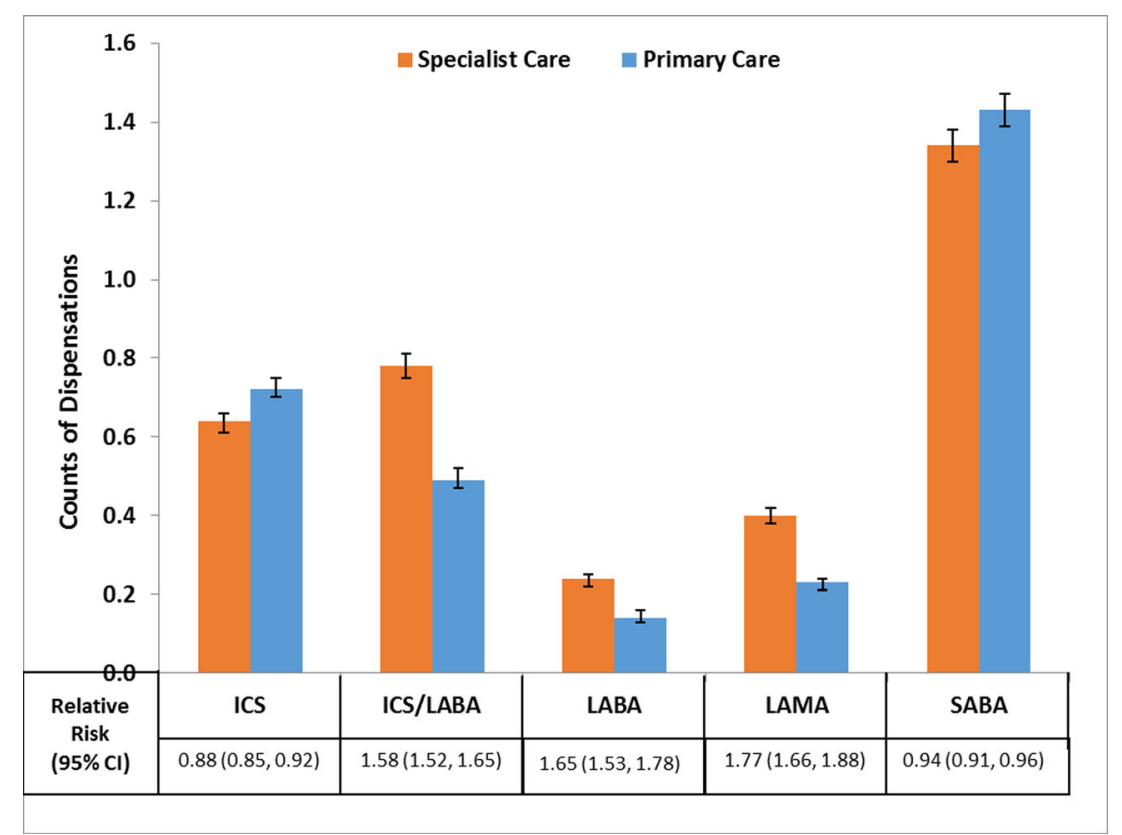

Fig. 1 Medication uses during the 90-day, post-COPD-hospitalization exposure window. ICS inhaled corticosteroids, ICS/LABA inhaled corticosteroid/long-acting $\beta$ agonist combination therapy, LABA long-acting $\beta$ agonists, LAMA long-acting muscarinic antagonists, SABA short-acting $\beta$ agonists. Relative risks and $P$ values were obtained from the Poisson regression analysis. 


\section{DISCUSSION}

To the best of our knowledge, this is the first study to evaluate the impact of care specialty on long-term medical costs of COPD. Following an incident COPD-related hospitalization, one third of patients were initially referred to a respiratory specialist and most $(92 \%)$ were matched to a comparable generalist-care recipient. Using an ITT approach, we showed that the specialist care cohort incurred moderately higher medical costs over time as compared with the primary care cohort. This was despite the rigorous adjustment for disease severity and clinically similar long-term survival rates of the two groups. This cost gap was mainly driven by higher medication costs (particularly related to COPD-specific medications) in the specialist group. These findings are interpretable to the specialist-care recipients who could receive either specialist or generalist care. A small fraction (8\%) of specialistcare recipients could not find a match and were excluded. Those were likely to be very severe patients who would not be assigned to generalist care.

Previous studies comparing quality of care specialty were mainly focused on its consistency with COPD management guidelines. ${ }^{34}$ Consistent with existing evidence, ${ }^{10-12}$ we found that specialists followed guideline-recommended pharmacological treatments more rigorously, including more prescriptions of ICS/LABA and certain pharmacological therapy (e.g., LAMA) after an inpatient episode of COPD exacerbation. The initial specialist-care recipients also incurred higher COPD medication costs over time. These differences may in part be driven by BC's drug plan policies wherein generalists have to apply for authorization to prescribe medications like LAMA or LABA/LAMA combination to each patient, whereas respirologists have full authority in these prescriptions. ${ }^{35}$ It remains unclear whether these medications prolong survival in $\mathrm{COPD},{ }^{36-38}$ but our cohorts were generally old and severe, and might have already missed the opportunity for COPD medications to affect survival. Reported in a small COPD sample, ${ }^{11}$ generalists tended to do better in smoke cessation education and vaccine prophylaxis than specialists. Smoke cessation is the only proven intervention to ameliorate disease progression in advanced COPD. ${ }^{39}$ Unfortunately, BC's administrative data do not capture smoking status, over-thecounter cessation medications, or online and public cessation counseling. Similarly, vaccinations in a pharmacy or community setting are not captured in administrative data. These interventions might act on the causal pathway between care specialty and costs and thus should not be adjusted for, but their potential mediating roles merit future research attention.

Canada's public healthcare system requires patients in an outpatient setting to first seek medical attention through general practitioners. ${ }^{40}$ The provision of specialist care tends to differ by place of residence; our final cohorts were already matched on health services delivery area ${ }^{41}$ to control for such differences. In the case of hospitalizations, the attending physician would be responsible for the post-discharge referral 
decision. On the other hand, given the temporal separation and rigorous matching on disease severity, pre-admission care specialty was unlikely to affect the relationship between post-discharge care specialty and cost outcomes.

Under such system, current findings indicate more intensive care among the post-discharge specialist-care recipients, as reflected by their overall higher costs of medications and outpatient visits. Their higher costs of COPD-related hospitalizations, however, could reflect either more elective referral to hospital, closer hospital-physician affiliation, or a form of "detection bias" in which an episode of acute respiratory illness is more likely to be classified as COPD-related if the prior diagnosis of COPD was made by a specialist. Otherwise, it could also indicate greater long-term disease severity (residual confounding), but the likelihood and the extent of such confounding should be low considering our rigorous matching strategy for the severity of COPD and the index hospitalization. Moreover, given the long wait time in $\mathrm{BC}$ for specialist referrals (9-12 weeks during 1997-2013 ${ }^{42}$ ), our choice of post-discharge 90-day window was to capture the initial post-discharge referral but not the cross-over ones. Meanwhile, frailty's role was uncertain, and as there were signs, the specialist group actually had slightly lower burden of comorbidity (e.g., modestly better survival and lower costs of comorbidity-related hospitalizations). Interestingly, the specialist group also incurred lower costs of community care. In part, this may relate to hospital-based specialists not being aware of the availability of different community-based services, but we need more evidence to confirm this hypothesis.

The estimates of survival-adjusted medical costs after an incident severe COPD exacerbation and how post-discharge referral patterns affect it over time have important implications on resource allocation decisions and clinical management strategies. However, our findings should be interpreted within the context of costs. The overall cost gap was relatively small (6\% increase in the specialist group over 5 years) and mainly driven by medication costs, which could indicate higher adherence to guideline-recommended medications in the specialty care group. To obtain a more complete picture, future studies should investigate into other policy-relevant outcomes such as health-related quality of life and functional status. Meanwhile, the association between within-hospital management and post-discharge referral merits further investigation as it would improve the interpretation of current results.

This study has several limitations. First, the BC administrative data did not fully capture spirometry measurements. Thus, we were unable to classify COPD clinical severity using the Global Initiative for Obstructive Lung Disease (GOLD)
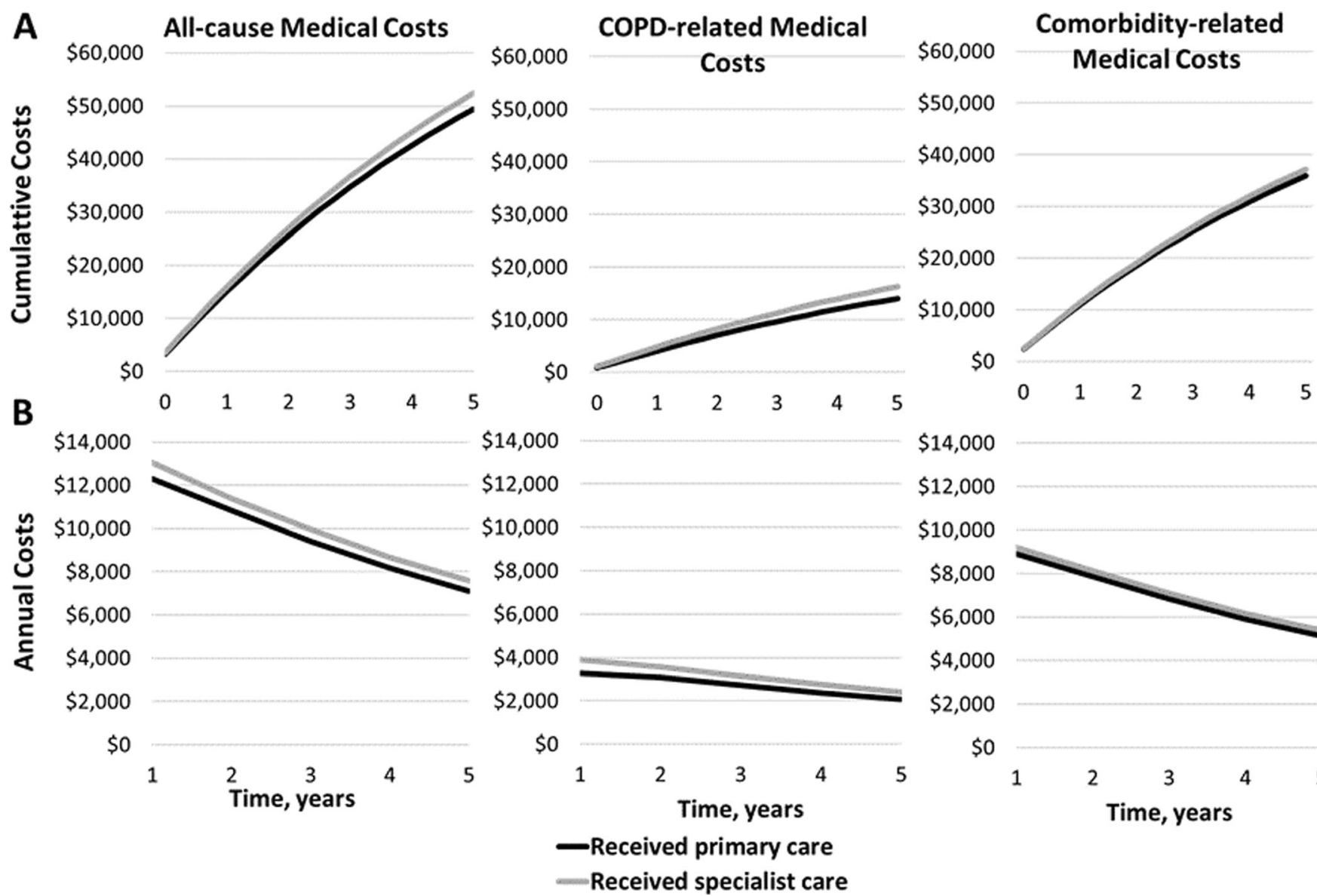

$\$ 14,000$

$\$ 12,000$

$\$ 10,000$

$\$ 8,000$

$\$ 6,000$

$\$ 4,000$

$\$ 2,000$

$\$ 0$

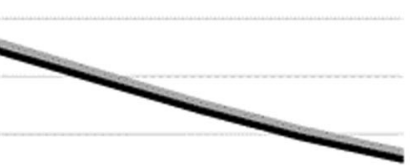

1

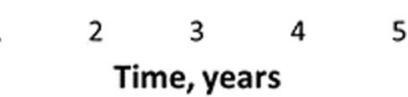

- Received primary care
Received specialist care

Fig. 3 Survival-adjusted 5-year medical costs for patients who received different specialty of care following an incident COPD hospitalization. a Cumulative costs per person. b Annual costs per person. Left panel: all-cause direct medical costs; middle panel: COPD-related medical costs; right panel: comorbidity-related medical costs. 
criteria. ${ }^{1}$ However, our matching strategy was likely to have sufficiently controlled for between-cohort differences in COPD severity. A claims-based model which included age, sex, comorbidities, COPD-related, and all-cause healthcare utilizations had $81 \%$ accuracy in predicting the severe and very severe COPD categories. ${ }^{43}$ All these variables were included in our propensity score matching. We further matched on COPD complexity, severity of index hospitalizations, SES, health services delivery area, calendar effect, and seasonality. Such matching strategy was more meticulous than a recent claims-based study which successfully controlled for COPD severity in a more confounding-prone context (e.g., inhaled controller therapies of different intensity ${ }^{44}$ ). Second, our assessment of exposure was performed in a fixed time window, whereas care specialty may change over time. This is not a limitation per se, as ITT provides valid ${ }^{45}$ and relevant inference to address our research questions, whereas time-dependent analysis is subject to confounding by indication and simultaneity bias where the exposure and the outcome jointly determine each other. ${ }^{46}$ Third, the suboptimal accuracy of ICD codes might cause specialtyrelated differences in the accuracy of COPD diagnoses. ${ }^{47}$ However, such likelihood was considered low because our cohorts were only consisted of the newly hospitalized patients who were matched on COPD severity to further improve homogeneity. Chart review studies have demonstrated that COPD as the primary reason for inpatient admission has high specificity (86\%) in identifying COPD patients. $^{23}$ Last but not least, we could not match for previous emergency department visits due to COPD exacerbations, because such information was not specifically captured in the $\mathrm{BC}$ administrative data. ${ }^{31}$ Nonetheless, our cohorts were similar in terms of COPD-related healthcare utilizations and COPD complexity at baseline, while the latter was directly validated on the incidence of COPD exacerbations. ${ }^{26}$

To conclude, among patients who experienced an incident hospitalization due to an acute COPD-related exacerbation, those who initially received specialist care incurred moderately higher long-term survival-adjusted medical costs compared to their counterparts under generalist care. The main drivers of this cost gap were the higher costs of medications particularly COPD-related medications in the specialist group. These results provide first insights into the economic implications of referral decision following an incident severe exacerbation of COPD, and inspire further investigations into the effects of care specialty on policyrelevant outcomes such as health-related quality of life.

Acknowledgements: WC had full access to all of the data in the study and takes responsibility for the content of the manuscript, including the integrity of the data and the accuracy of the data analysis. WC, JMF, DS, and MS conceived and designed the study. WC analyzed the data and wrote the first draft of the manuscript. WC, JMF, DS, and MS contributed to the interpretation of the data and clinical inputs. All authors were involved in the revision of the manuscript for important intellectual content and approved the final version to be published.

Corresponding Author: J. Mark FitzGerald, MD; UBC Division of Respiratory Medicine, Department of Medicine, The Lung Centre Gordon and Leslie Diamond Health Care Centre, 7th Floor, 2775 Laurel Street, Vancouver, BC V5Z 1M9, Canada (e-mail: Mark. Fitzgerald@vch.ca).

Funding sources This study was funded by the Canadian Respiratory Research Network (CRRN). CRRN is supported by grants from the Canadian Institutes of Health Research (CIHR)-Institute of Circulatory and Respiratory Health, Canadian Lung Association (CLA)/Canadian Thoracic Society (CTS), British Columbia Lung Association, and Industry Partners Boehringer-Ingelheim Canada Ltd, AstraZeneca Canada Inc., and Novartis Canada Ltd. Funding for training of postdoctoral student and new investigators within the network was supported by the above funding Sponsors and as well by GlaxoSmithKline Inc. The funders had no role in the study design, data collection and analysis, or preparation of the manuscript. Dr. Sadatsafavi receives salary support from Michael Smith Foundation for Health Research and Canadian Institutes of Health Research.

\section{Compliance with ethical standards:}

Conflict of interest: The authors declare no conflict of interests.

\section{REFERENCES}

1. Vogelmeier CF, Criner GJ, Martinez FJ, et al. Global Strategy for the Diagnosis, Management, and Prevention of Chronic Obstructive Lung Disease 2017 Report: GOLD Executive Summary. Am J Respir Crit Care Med 2017. https://doi.org/10.1164/rccm.201701-0218PP.

2. Sin DD, Anthonisen NR, Soriano JB, Agusti AG. Mortality in COPD: Role of comorbidities. Eur Respir J 2006;28(6):1245-1257. https://doi. org/10.1183/09031936.00133805.

3. The Human and Economic Burden of COPD - A Leading Cause of Hospital Admission in Canada | Canadian Respiratory Guidelines. http://www.respiratoryguidelines.ca/the-human-and-economic-burden-of-copd-a-leading-cause-of-hospital-admission-in-canada. Accessed 2 Feb 2018.

4. Wier LM, Elixhauser A, Pfuntner A, Au DH. Overview of Hospitalizations among Patients with COPD, 2008: Statistical Brief \#106. In: Healthcare Cost and Utilization Project (HCUP) Statistical Briefs. Rockville (MD): Agency for Healthcare Research and Quality (US); 2006. http:// www.ncbi.nlm.nih.gov/books/NBK53969/. Accessed 2 Feb 2018.

5. World Health Organization. Burden of COPD. WHO. http://www.who. int/respiratory/copd/burden/en/. Accessed 2 Feb 2018.

6. Mittmann N, Kuramoto L, Seung SJ, Haddon JM, Bradley-Kennedy C, Fitzgerald JM. The cost of moderate and severe COPD exacerbations to the Canadian healthcare system. Respir Med 2008;102(3):413-421. https://doi.org/10.1016/j.rmed.2007.10.010.

7. Ford ES, Murphy LB, Khavjou O, Giles WH, Holt JB, Croft JB. TOtal and state-specific medical and absenteeism costs of copd among adults aged $\geq$ 18 years in the united states for 2010 and projections through 2020 . Chest 2015;147(1):31-45. https://doi.org/10.1378/chest.14-0972.

8. Chapman KR, Bourbeau J, Rance L. The burden of COPD in Canada: results from the Confronting COPD survey. Respir Med 2003;97 Suppl C:S23-31.

9. Edwards ST, Mafi JN, Landon BE. Trends and Quality of Care in Outpatient Visits to Generalist and Specialist Physicians Delivering Primary Care in the United States, 1997-2010. J Gen Intern Med 2014;29(6):947-955. https://doi.org/10.1007/s11606-014-2808-y.

10. Pothirat C, Liwsrisakun C, Bumroongkit C, Deesomchok A, Theerakittikul T, Limsukon A. Comparative study on health care utilization and hospital outcomes of severe acute exacerbation of chronic obstructive pulmonary disease managed by pulmonologists vs internists. Int J Chron Obstruct Pulmon Dis 2015; 10:759-766. https://doi.org/10. 2147/COPD.S81267. 
11. Diaz-Fuentes G, Lakshmi V, Blum S, Sy S, Escalera E. Chronic Obstructive Pulmonary Disease: Comparison of Care by Specialists and Generalists in an Inner-City Hospital. Internet $J$ Pulm Med. 2004;5(1). http://ispub.com/IJPM/5/1/12172. Accessed 2 Feb 2018.

12. Bourbeau J, Sebaldt RJ, Day A, et al. Practice patterns in the management of chronic obstructive pulmonary disease in primary practice: The CAGE study. Can Respir J J Can Thorac Soc 2008;15(1): 13-19.

13. Murray CJ, Lopez AD. Global mortality, disability, and the contribution of risk factors: Global Burden of Disease Study. Lancet Lond Engl 1997;349(9063):1436-1442. https://doi.org/10.1016/S0140-6736(96) 07495-8.

14. Basu A, Manning WG. Estimating lifetime or episode-of-illness costs under censoring. Health Econ 2010;19(9):1010-1028. https://doi.org/ 10.1002/hec. 1640 .

15. Government of Canada SC. Population by sex and age group, by province and territory (Number, both sexes). http://www.statcan.gc.ca/tablestableaux/sum-som/101/cst01/demo3la-eng.htm. Published September 26, 2014. Accessed $2 \mathrm{Feb} 2018$.

16. British Columbia Ministry of Health [creator]. Consolidation File (MSP Registration \& Premium Billing). Population Data BC[publisher]. Data Extract. MOH. 2014. Available at: http://www.popdata.bc.ca/data. Accessed 2 Feb 2018

17. BC Vital Statistics Agency [creator]. Vital Statistics Deaths. Population Data BC [publisher]. Data Extract. BC Vital Statistics Agency. 2014 Available at: http://www.popdata.bc.ca/data. Accessed Feb 22018.

18. CIHI [creator]. Discharge Abstract Database (Hospital Separations). Population Data BC [publisher]. Data Extract. MOH. 2014. Available at: http://www.popdata.bc.ca/data. Accessed 2 Feb 2018.

19. M British Columbia Ministry of Health [creator]. Medical Services Plan (MSP) Payment Information File. Population Data BC [publisher]. Data Extract. MOH. 2014. Available at: http://www.popdata.bc.ca/data. Accessed 2 Feb 2018.

20. British Columbia Ministry of Health [creator]. PharmaNet. BC Ministry of Health [publisher]. Data Extract. Data Stewardship Committee. 2013. Available at: http://www.popdata.bc.ca/data. Accessed 2 Feb 2018.

21. British Columbia Ministry of Health[creator]. Home and Community Care. BC Ministry of Health [publisher].Data Extract. MOH. 2014. Available from: http://www.popdata.bc.ca/data. Accessed 2 Feb 2018.

22. (CIHI) CI for HI. CIHI Data Guality Study of the DAD 2009-2010 Discharge Abstract Database. https://secure.cihi.ca/estore/ productFamily.htm?pf=PFC1762\&lang=en\&media=0. Published April 27, 2012. Accessed 2 Feb 2018

23. Gershon AS, Wang C, Guan J, Vasilevska-Ristovska J, Cicutto L, To T. Identifying individuals with physcian diagnosed COPD in health admin istrative databases. COPD 2009;6(5):388-394.

24. Hernán MA, Alonso A, Logan R, et al. Observational studies analyzed like randomized experiments: an application to postmenopausal hormone therapy and coronary heart disease. Epidemiol Camb Mass 2008;19(6):766-779. https://doi.org/10.1097/EDE.0b013e3181875e61.

25. Sadatsafavi M, FitzGerald M, Marra C, Lynd L. Costs and health outcomes associated with primary vs secondary care after an asthmarelated hospitalization: a population-based study. Chest 2013;144(2):428-435. https://doi.org/10.1378/chest.12-2773.

26. Mapel DW, Dutro MP, Marton JP, Woodruff K, Make B. Identifying and characterizing COPD patients in US managed care. A retrospective, cross sectional analysis of administrative claims data. BMC Health Serv Res 2011;11:43. https://doi.org/10.1186/1472-6963-11-43.

27. Charlson ME, Pompei P, Ales KL, MacKenzie CR. A new method of classifying prognostic comorbidity in longitudinal studies: development and validation. J Chronic Dis 1987;40(5):373-383.

28. Poole B, Robinson S, MacKinnon M. Resource Intensity Weights and Canadian hospital costs: some preliminary data. Healthc Manag Forum Can Coll Health Serv Exec Forum Gest Soins Santé Collège Can Dir Serv Santé 1998;11(1):22-26.

29. Chen W, Lynd LD, FitzGerald JM, et al. Excess medical costs in patients with asthma and the role of comorbidity. Eur Respir J 2016;48(6):15841592. https://doi.org/10.1183/13993003.01141-2016.
30. Chen W, Lynd LD, FitzGerald JM, Sadatsafavi M. Influences of Socioeconomic Status on Costs of Asthma Under Universal Health Coverage. Med Care 2016;54(8):789-795. https://doi.org/10.1097/ MLR.0000000000000563.

31. McKendry R, Reid RJ, McGrail KM, et al. Emergency Rooms in British Columbia: A Pilot Project to Validate Current Data and Describe Users. Vancouver (BC): Centre for Health Services and Policy Research; 2002.

32. Cohen J. CHAPTER 2 - The t Test for Means. In: Cohen J, ed. Statistical Power Analysis for the Behavioral Sciences (Revised Edition). Academic Press; 1977:19-74. http://www.sciencedirect.com/science/article/pii/ B9780121790608500074. Accessed 2 Feb 2018.

33. Austin PC, Urbach DR. Using G-computation to estimate the effect of regionalization of surgical services on the absolute reduction in the occurrence of adverse patient outcomes. Med Care 2013;51(9):797-805. https://doi.org/10.1097/MLR.0b013e31829a4fb4.

34. Vestbo J, Hurd SS, Agusti AG, et al. Global strategy for the diagnosis, management, and prevention of chronic obstructive pulmonary disease: GOLD executive summary. Am J Respir Crit Care Med 2013;187(4):347365. https://doi.org/10.1164/rccm.201204-0596PP.

35. Health M of. Special Authority - Province of British Columbia. https:// www2.gov.bc.ca/gov/content/health/practitioner-professional-resources/pharmacare/prescribers/special-authority\#Druglist. Accessed 2 Feb 2018.

36. Calverley PMA, Anderson JA, Celli B, et al. Salmeterol and fluticasone propionate and survival in chronic obstructive pulmonary disease. N Engl J Med 2007;356(8):775-789. https://doi.org/10.1056/NEJMoa063070.

37. Mathioudakis AG, Kanavidis $\mathbf{P}$, Chatzimavridou-Grigoriadou V, et al. Tiotropium HandiHaler improves the survival of patients with COPD: a systematic review and meta-analysis. J Aerosol Med Pulm Drug Deliv 2014;27(1):43-50. https://doi.org/10.1089/jamp.2012.1012.

38. Singh S, Loke YK, Enright PL, Furberg CD. Mortality associated with tiotropium mist inhaler in patients with chronic obstructive pulmonary disease: systematic review and meta-analysis of randomised controlled trials. BMJ 2011;342:d3215

39. National Clinical Guideline Centre (UK). Ch 7. Managing Stable COPD. In: Chronic Obstructive Pulmonary Disease: Management of Chronic Obstructive Pulmonary Disease in Adults in Primary and Secondary Care. Royal College of Physicians (UK); 2010. https://www.ncbi.nlm.nih.gov/books/ NBK65045/. Accessed 2 Feb 2018.

40. Health $\mathrm{M}$ of. Chronic Obstructive Pulmonary Disease (COPD): Diagnosis and Management - Province of British Columbia. https://www2.gov.bc ca/gov/content/health/practitioner-professional-resources/bc-guidelines/copd . Accessed 2 Feb 2018.

41. Services M of TI and C. Health Boundaries - Province of British Columbia https://www2.gov.bc.ca/gov/content/data/geographic-data-services/ land-use/administrative-boundaries/health-boundaries. Accessed 2 Feb 2018.

42. Waiting Your Turn: Wait Times for Health Care in Canada, 2016 Report. Fraser Institute. http://bit.ly/2gHMwL2?_unam=b07cbf6-15f4a7f006e72453276-6\&_ga=GA1.2.158609998.1508783358. Published November 23, 2016. Accessed 2 Feb 2018.

43. Macaulay D, Sun SX, Sorg RA, et al. Development and validation of a claims-based prediction model for COPD severity. Respir Med 2013;107(10):1568-1577. https://doi.org/10.1016/j.rmed.2013.05.012.

44. Gershon AS, Campitelli MA, Croxford R, et al. Combination long-acting $\beta$-agonists and inhaled corticosteroids compared with long-acting $\beta$ agonists alone in older adults with chronic obstructive pulmonary disease. JAMA 2014;312(11):1114-1121. https://doi.org/10.1001/ jama.2014.11432.

45. Gupta SK. Intention-to-treat concept: A review. Perspect Clin Res 2011;2(3):109-112. https://doi.org/10.4103/2229-3485.83221.

46. Daniel RM., Cousens SN., De Stavola BL., Kenward MG, Sterne JAC. Methods for dealing with time-dependent confounding. Stat Med 2013;32(9): 1584-1618. https://doi.org/10.1002/sim.5686.

47. Prieto-Centurion V, Rolle AJ, Au DH, et al. Multicenter Study Comparing Case Definitions Used to Identify Patients with Chronic Obstructive Pulmonary Disease. Am J Respir Crit Care Med 2014;190(9):989-995. https://doi.org/10.1164/rccm.201406-11660C. 